\title{
A TRANSAÇÃO COMO FATOR ESTRUTURANTE DA CADEIA DE SUPRIMENTO DO BIODIESEL NO RIO GRANDE DO SUL
}

\section{1- Manoela Silveira dos Santos*}

Doutoranda em Administração pela Universidade Federal do Rio Grande do Sul (UFRGS), Brasil. manoela81@yahoo.com.br

http://lattes.cnpq.br/3160353255727010

\section{2- Antonio Domingos Padula}

Doutor em Administração pela Université de Sciences Sociales de Grenoble, França.

Professor do Programa de Pós-Graduação em Administração da Universidade Federal do Rio Grande do Sul (UFRGS), Brasil.

adpadula@ea.ufrgs.br

http://lattes.cnpq.br/3203712465096936 
A TRANSAÇÃO COMO FATOR ESTRUTURANTE DA CADEIA DE SUPRIMENTO DO BIODIESEL NO RIO GRANDE DO SUL

\section{RESUMO}

O presente artigo analisa a influência das transações que ocorrem entre os membros de cadeias de suprimento de biodiesel no Rio Grande do Sul sobre as estruturas destas. Foi realizado um estudo de casos múltiplos em duas das sete cadeias de suprimento de biodiesel localizadas no estado. Para a coleta de dados foram utilizadas diferentes fontes de evidência: revisão bibliográfica, conversas informais com os atores das cadeias, participação em reuniões juntamente com alguns representantes dos elos das cadeias; relatórios do governo; entrevistas não-estruturadas com representantes dos grupos de fornecimento, de consumo e alguns membros de suporte da cadeia e entrevistas semi-estruturadas com representantes das usinas produtores de biodiesel. Observou-se que os atributos da transação e os pressupostos comportamentais impactaram na estrutura da Cadeia de Suprimento do Biodiesel localizadas no Rio Grande do Sul, algumas das descobertas relevantes são: a presença de oportunismo e incertezas nas transações entre os produtores familiares e usinas, a falta de fidelidade nas relações entre produtores familiares/cooperativas, produtores familiares/usinas e cooperativas/usinas faz com que as usinas tenham muitas trocas de fornecedores de grãos, e a redução do oportunismo e incerteza a partir de uma maior frequência das transações e dos contratos assinados sob o Selo Combustível Social.

\section{Palavras-chave}

Biodiesel, Cadeia de Suprimento, Rio Grande do Sul, Programa Nacional de Produção e Uso do Biodiesel (PNPB), Transação.

\section{TRANSACTION AS A STRUCTURING FACTOR OF BIODIESEL SUPPLY CHAIN IN RIO GRANDE DO SUL}

\section{ABSTRACT}

The present article intend to analyze the transaction influence that occur between members of biodiesel supply chain in Rio Grande do Sul on these structure. A multiple cases study was performed in two of the six biodiesel supply chain localized in Rio Grande do Sul, for date collection were used different sources of evidence, such as: literature review, informal conversation with the actors of the chain, participation in meeting with same representatives of the chain links, government reports, non-structured interviews with representatives of supply, consumption and support group, and semi-structured interviews with representatives of biodiesel plants. It was identified that attributes of transaction and behavioral assumption have impact on the structure of the biodiesel supply chain in Rio Grande do Sul, some relevant findings are: the presence of opportunism and uncertainty in transactions between family farmers and biodiesel mills, the lack of fidelity in the relation between family farmers/cooperatives, family farmers/biodiesel mills and cooperatives/biodiesel mills resulted in constant change in the grain supply base of the biodiesel plants, and also was observed a reduction of opportunism and uncertainty due a greater transactions frequency, and in consequence of the contracts signed under Social Fuel Seal.

\section{Keywords}

Biodiesel; Supply Chain ; Rio Grande do Sul; National Program of Biodeisel Production and Use (PNPB); Transaction. 


\section{Introdução}

As energias renováveis como alternativas de substituição aos combustíveis fósseis na matriz energética estão cada vez mais presentes nas discussões políticas, econômicas e ambientais no contexto internacional. Com a crescente contenda acerca da necessidade de substituição do petróleo, os bicombustíveis encontram-se no centro das recentes defesas e críticas a essa substituição. Alguns dos motivos que estimularam a criação e o desenvolvimento de um mercado global para este tipo de combustível, em destaque o etanol e o biodiesel, foram o aquecimento global e as incertezas quanto aos preços e a oferta de petróleo para as próximas décadas.

No Brasil, o tema biodiesel tomou força com o Programa Nacional de Produção e Uso do Biodiesel (PNPB) implementado pelo governo federal. Esse programa incorporou o biodiesel a matriz energética brasileira, a partir da lei 11.097, sancionada no dia 13 de janeiro de 2005 (Brasil, 2009a), impulsionando a estruturação deste setor. Os objetivos do PNPB são: dar condições de funcionamento ao mercado do biodiesel no Brasil; incentivar a diversificação da oferta de matérias-primas energéticas para a produção de biodiesel em todas as regiões do País; e integrar a agricultura familiar na cadeia produtiva do biodiesel (PNPB, 2005).

A relevância da participação do biodiesel na matriz energética brasileira está fundamentada nas seguintes razões: (i) é um meio de reduzir a dependência do petróleo e diversificar a matriz energética brasileira, (ii) é uma forma de ampliar o mercado de oleaginosas no país, (iii) é mais uma oportunidade para a inclusão social da agricultura familiar, (iv) contribuirá para a redução da emissão de poluentes, (v) e possibilitará a criação de emprego e renda em várias regiões no país (Santos, 2009). Esses são alguns dos motivos que faz com que o governo federal, ainda hoje, mantenha sua política de incentivo ao biodiesel.

Em quase 9 anos de existência, o PNPB trouxe avanços para a cadeia nacional de produção de biodiesel, principalmente: no processo de comercialização do biodiesel por meio de leilões, nas questões de logística de distribuição, na introdução de mecanismos de incentivo à agricultura familiar e no aumento do percentual de mistura obrigatória do biodiesel ao diesel. Observa-se que o quadro regulatório, assim como os programas e incentivos para a cadeia do biodiesel definidos pelo governo federal direcionaram as decisões dos agentes da cadeia do biodiesel, moldando a estrutura das cadeias de suprimentos.

No entanto, além das pressões institucionais a estrutura da cadeia de suprimento também é influenciada por fatores internos. A transação entre os elos da cadeia é um dos fatores que contribuem com a estruturação da cadeia de suprimento. Este artigo propõe analisar a forma como as transações que ocorrem entre os diversos elos da cadeia de suprimento biodiesel no Rio Grande do Sul, influenciaram a estrutura desta. Para tal fim o artigo contará com a análise de duas cadeias de suprimento de biodiesel no Rio Grande do Sul e dos elementos das transações que ocorrem entre os agentes destas cadeias. Os resultados da análise identificam as formas tomadas pelas cadeias a partir das características das transações e explicam o comportamento de alguns membros da cadeia.

O presente artigo está organizado da seguinte forma: (i) revisão teórica sobre Cadeias de Suprimento e sobre as transações, trazendo especialmente conceitos da Economia dos Custos de Transação a situação do biodiesel no Brasil e no Rio Grande do Sul; (ii) a metodologia utilizada na realização do estudo; (iii) a caracterização das duas cadeias estudadas e a análise dos componentes da transação que ocorrem entre os membros da cadeia de biodiesel, e por fim (iv) as considerações finais deste artigo.

\section{Quadro Teórico}

Cadeia de Suprimento é um arranjo interorganizacional que busca aumentar a competitividade das organizações que a compõem, uma vez que o desempenho global é reflexo do desempenho individual dos seus membros. A Gestão da Cadeia de Suprimento está relacionada à gestão do fornecimento e demanda entre os membros pertencentes ao sistema, com a função de integrar os processos entre empresas dentro de um modelo de negócio coerente, coeso e de alta performance. Tem perfil econômico, procurando ser eficiente e "cost-effective" ao longo de todo o sistema, por meio da integração eficiente dos processos de negócios da cadeia (Cooper \& Ellram, 1993; Croxton, García-Dastugue, Lamber \& Rogers, 2001; Fredendall \& Hill, 2001; Sinchi-Levi, Kaminsky \& Simchi-Levi, 2000).

Para Zylbersztajn e Farina (1999) é vista como um conjunto de contratos definidos por um modo específico de governança, que arquiteta resultados por meio do alinhamento das características das 
transações e do ambiente institucional. Por se tratar de uma relação interorganizacional, as organizações pertencentes à cadeia cooperam entre si, coordenando suas ações individuais, para atingir seus objetivos individuais e os da cadeia (Saes, 2000). Os elementos e processos que compõem as atividades individuais dos membros, em conjunto definem as atividades e a estrutura da própria cadeia, que também são influenciadas pela forma como as transações se configuram e pelo ambiente institucional no qual se insere.

Para Lambert e Cooper (2000) a estrutura da cadeia de suprimento é composta por três componentes essenciais: (i) a estrutura da cadeia de suprimento - configuração das empresas dentro da cadeia; (ii) os processos de negócios - atividades que produzem outputs com valor; e, (iii) os componentes de gestão - que gerenciam os processos de negócios. O mapeamento da estrutura de relações da cadeia e a identificação dos processos de negócios-chaves que integram os membros são fundamentais para o processo de planejamento e para a implementação da gestão da cadeia de suprimento, sendo fundamental a compreensão da própria cadeia, sem a qual as atividades de planejamento e gestão não são possíveis.

A cadeia de suprimento é constituída de uma estrutura horizontal, que compreende o número de níveis existentes e uma estrutura vertical, representada pela quantidade de membros (fornecedores e clientes) que mantêm transações em cada um dos níveis da estrutura horizontal (Lambert \& Cooper, 2000). Os membros da cadeia de suprimento que estão localizados a montante da empresa focal pertencem ao grupo de fornecimento, já os membros que se encontram num ponto a jusante são do grupo de consumo (D'Cruz \& Rugman, 1997; Fredendall \& Hill, 2001; Lambert, 2001). A inclusão ou exclusão de um membro, independente da sua posição, influi não só a estrutura da cadeia de suprimento, mas também, as conexões existentes entre os demais membros.

O processo de negócio da cadeia de suprimento é a forma como as atividades internas das organizações são estruturadas e geridas para criar valor ao consumidor final (Hammer \& Champy, 1994; Harrington, 1993). Permeiam os elos da cadeia e a maneira como estes processos são organizados, sendo um fator crítico para o desempenho e a configuração da cadeia. Os processos se complementam fornecendo inputs (informações, recursos, etc.) para os outputs dos outros elos, assegurando a continuidade do processo ao longo da cadeia.

O Global Supply Chain Fórum - GSCF, conforme relatam Lambert e Cooper (2000) e Croxton et al. (2001), identificou oito processos de negócios-chave para a configuração da cadeia, que se assemelham aos levantados por Samaranayake (2005), são eles: (i) processo de gestão do relacionamento com o consumidor; (ii) processo de gestão do serviço ao consumidor; (iii) processo de gestão da demanda; (iv) processo de cumprimento das ordens dos clientes; (v) processo de gestão do fluxo de produção; (vi) processo gestão do relacionamento com o fornecedor; (vii) processo de desenvolvimento e comercialização; e, (viii) processo de retorno.

Existem alguns componentes de gestão comuns a todos os elos, a gestão destes determina o curso de ação dos negócios e a forma como a cadeia de suprimento é gerenciada e organizada. Para Cooper, Lambert e Pagh. (1997) os componentes podem ser divididos em dois grupos, o tecnológico/físico e o gerencial/comportamental. O primeiro grupo abrange os componentes tangíveis, mensuráveis e fáceis de serem modificados quando necessários, são eles: (i) o planejamento e controle, (ii) a estrutura de trabalho, (iii) a estrutura organizacional, (iv) a estrutura do fluxo de produto, (v) a estrutura do fluxo de informação e (vi) a estrutura do produto. Podem ser acrescidos a estes componentes a tecnologia, os contratos e os investimentos financeiros (Santos, 2009).

Já o grupo gerencial/comportamental tem um perfil diferente e é composto pelos componentes menos tangíveis e visíveis pelos indivíduos da empresa, e as mudanças são mais difíceis de serem promovidas. Fazem parte desse grupo: (i) os métodos de gestão, (ii) a estrutura de poder e liderança, (iii) a estrutura de risco e recompensa e (iv) a cultura e atitude. Os elementos voltados à questão comportamental influenciam os componentes localizados no grupo tecnológico/físico.

Além dos componentes chave da cadeia de suprimento, o ambiente institucional no qual a cadeia se insere e as transações que ocorrem entre seus membros, também influenciam a forma como a cadeia se organiza. O ambiente institucional é entendido como o local onde existe um conjunto de regras formais e informais que orientam as ações coletivas das organizações que operam nele.

Para Coase (1937) a razão da existência das organizações (firmas) é o fato de algumas vezes o custo de gerenciar as transações econômicas no mercado ser maior do que gerenciá-los dentro dos limites da 
organização, ou seja, ela é uma alternativa ao mercado. Ao decidir ir ao mercado, por ser mais vantajoso do que produzir internamente, a firma passa a incorrer em custos de transação (Williamson, 1996).

Este custo incide sobre a firma por esta não possuir as informações corretas ou suficientes para colocar o seu produto no mercado e, por conseguinte, ser referência de preço. Portanto, a firma que vai ao mercado transacionar depois que as outras já estão presentes, passa a ter um custo de transação, que é a diferença entre o preço da firma e o preço praticado no mercado. Williamson (1985) defende a existência dos custos de transação ex-ante e ex-post, sendo o primeiro referente aos custos de desenho, negociação e salvaguarda nas transações por meio de contratos formais ou informais. Esses contratos mesmo com salvaguardas e negociações permanecem incompletos, deixando a transação passível a falhas, erros, omissões, desalinhamentos e alterações contingenciais. Em decorrência, a firma incorre em custos ex-post, que são provenientes do monitoramento, alinhamento e adaptações feitas nos contratos.

A governança existe como meio de modelar a ordem, reduzir os conflitos e realizar ganhos mútuos entre os agentes econômicos da transação (Williamson, 2000). A estrutura de governança pode ser entendida como uma função das características da transação e do ambiente institucional (Zylbersztajn \& Farina, 1999). Assim, a decisão sobre qual estrutura de governança deve ser adotada para governar as transações depende dos fatores que definem as transações, sendo, os pressupostos comportamentais (racionalidade limitada e oportunismo) e os atributos da transação (incerteza, especificidade e frequência).

Os dois pressupostos comportamentais ligados aos agentes econômicos envolvidos na transação, que sustentam a Economia dos Custos de Transação são a racionalidade limitada e o oportunismo. Estes atributos influenciam a escolha do contrato a ser firmado na transação e na estrutura de governança mais adequada para a situação. Simon (1997) entende que os atores econômicos são intencionalmente racionais, mas de modo limitado, uma vez que, devido às restrições cognitivas da mente humana, não é possível concretizar a intenção por completo, existindo então uma racionalidade limitada. Ela existe pela incapacidade do homem em obter todas as informações e conhecimentos disponíveis e em prever todos os eventos relacionados à transação, resultando em custos de transação.

Para Williamson $(1985,2000)$, o oportunismo se refere à busca pelo interesse próprio com esperteza, que significa aproveitar as chances com astúcia, podendo incluir também ações de má intenção. Sabendo que existem agentes que podem se utilizar do oportunismo em uma transação, as partes devem ficar atentas para que este não seja utilizado em benefício restrito a apenas um dos agentes, neste contexto os contratos tem como função resguardar seus interesses. Os contratos surgem como meio de amparo às transações que ocorrem quando a firma passa a fazer parte do sistema econômico, procurando reduzir os riscos e a variabilidade, dando mais valor à transação e segurança durante a mesma (Zylbersztajn, 2005).

Assim, os contratos passam a serem vistos como mecanismos importantes para a transação. O tipo de perigo contratual e as salvaguardas que são impostas à organização influem no tipo de governança que regerá a transação. A governança pode ser descrita dentro de um continuum, partindo do mercado (decisão da organização em comprar) para a hierarquia (integração vertical), sendo que as formas híbridas de governança se encontram entre esses dois extremos (Williamson, 1985). O custo efetivo do perigo é aliviado pela existência da governança, porque, quanto mais complexa for esta, maiores são as salvaguardas e mais custos burocráticos são incluídos (Williamson, 2000).

A especificidade do ativo está ligada à utilização e ao valor de mercado deste ativo, quanto maior a sua especificidade, maior será o seu valor por ter uma utilidade única, quanto maior forem as alternativas de uso, menor será a especificidade deste ativo e menor o seu valor de mercado. Segundo Williamson (1981, 1985), é a dimensão mais importante para descrever a transação, uma vez que o investimento realizado faz com que os agentes envolvidos na transação operem de forma bilateral.

Knight (1972) relaciona a incerteza à decorrência de situações não identificáveis; dessa forma, quanto maior o seu nível, mais complexas serão as formas de governança pela necessidade de salvaguardas melhor elaboradas. Associada a este atributo, está a racionalidade limitada do agente econômico, visto que ela está presente nas transações por não ser possível garantir o levantamento e a qualidade da totalidade de informações e as identificações de todas as possíveis alternativas.

A frequência, como atributo da transação, está ligada a constância com que as transações ocorrem entre dois agentes econômicos. Pode ser associada a confiança existente entre os agentes econômicos envolvidos, desta forma, quanto maior o número de transações entre eles, mais forte será a reputação construída, reduzindo a incerteza quanto aos possíveis comportamentos das partes e também o oportunismo da relação. 
Estes elementos definem a transação e, por conseguinte, a governança, que influenciam na forma como a organização se estrutura; portanto, podem ser vistos como os elementos teóricos que geraram e influenciam as respostas organizacionais. Sob essa perspectiva, é possível utilizar a Economia dos Custos de Transação para compreender a maneira como a cadeia de suprimento se desenha, sendo esta constituída por organizações que mantêm relações contratuais formais e informais.

As transações afetam a organização e a estrutura hierárquica da mesma, bem como a maneira da conversão das atividades econômicas internas em partes operativas, direcionando, assim, a composição interna da organização. Dessa forma, a análise no nível das transações em uma cadeia de suprimento auxilia na compreensão de como os elementos da transação determinam as ações e as estruturas organizacionais dos elos.

Com base nas variáveis levantadas elaborou-se um esquema de análise (Figura 1) que permitisse a identificação e apreciação da estruturação da cadeia de suprimento.

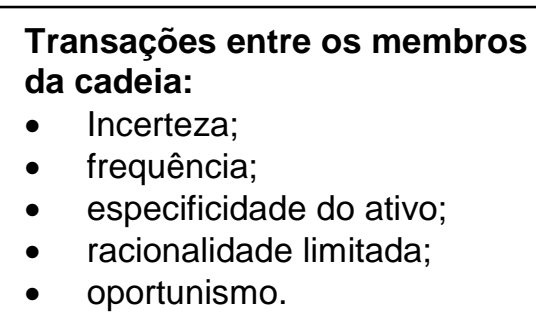

$\longleftrightarrow$\begin{tabular}{|llll|}
$\begin{array}{l}\text { Estrutura da } \\
\text { Suprimento } \\
\text { - Processos deia de } \\
\text { suprimento: }\end{array}$ & cadeia & de \\
\hline
\end{tabular}

Figura 1: Estrutura de análise para a estruturação da Cadeia de Suprimento

\subsection{Biodiesel no Brasil e no Rio Grande do Sul}

A participação do biodiesel na matriz energética brasileira é recente, em 2003 a partir do Decreto de 23/12/2003 da Casa Civil (Brasil, 2009b) a produção e o consumo de biodiesel passaram a ser legalmente estimulados no Brasil. Este foi o marco regulatório inicial para o setor de biodiesel e a partir da lei $n^{\circ}$ 11.097 de 2005 (Brasil, 2009a) foram estabelecidas as regras para introdução do biodiesel na matriz energética brasileira e os percentuais mínimos de mistura do biodiesel ao diesel comercializado no Brasil. $\mathrm{O}$ Programa Nacional de Produção e Uso do Biodiesel (PNPB) tem como diretrizes principais: (i) a implementação de forma sustentável da produção e uso do biodiesel, tanto técnica como economicamente, com o foco no desenvolvimento regional e na inclusão social, (ii) garantir preços competitivos, (iii) a qualidade e (iv) o suprimento do biodiesel (PNPB, 2005). Além de incentivar a produção do biodiesel a partir de diferentes oleaginosas para proporcionar a diversificação de fontes e regiões produtoras de matéria-prima.

Além da vantagem econômica que a produção de biodiesel proporciona, por meio da substituição da importação de óleo diesel, está presente também o aspecto social e ambiental, que são relevantes, sobretudo considerando a possibilidade de conciliar sinergicamente todas essas potencialidades. No que se refere às questões sociais, foi criado o Selo Combustível Social, um conjunto de medidas específicas que opera sobre vários processos relacionados ao biodiesel (tributação, comercialização, produção e fornecimento de matéria-prima). Para garantir que a agricultura familiar se tornasse um elo efetivo na cadeia de suprimento de biodiesel, o governo arquitetou o quadro institucional de forma a induzir os produtores de biodiesel a obterem o Selo Combustível Social, disponibilizando benefícios tributários às usinas de biodiesel, garantindo o acesso aos leilões de venda de biodiesel e facilitando o acesso a financiamento (SAF/MDA, 2009).

O enquadramento social de projetos ou empresas produtoras de biodiesel permite acesso a melhores condições de financiamento junto ao BNDES e a outras instituições financeiras. As indústrias produtoras também passam a ter direito a desoneração de alguns tributos, como o PIS/PASEP e a Cofins, desde que haja garantia de compra da matéria-prima a preços pré-estabelecidos, oferecendo segurança aos agricultores familiares. Para que a empresa consiga o Selo é necessário que adquira percentuais mínimos de matéria-prima do agricultor familiar de acordo a Instrução Normativa no 1 (Brasil, 2009c). Além disso, é exigida a presença e aval de um representante de classe da agricultura familiar (Sindicatos ou Federações filiadas à Confederação Nacional dos Trabalhadores na Agricultura - CONTAG, a Federação dos 
Trabalhadores da Agricultura Familiar - FETRAF, a Associação Nacional dos Pequenos Agricultores - ANPA, ou então outras instituições credenciadas pelo MDA) na negociação da compra de grãos entre os produtores familiares e usinas de biodiesel. A compra nas cooperativas é permitida desde que estas tenham a DAP - Declaração de Aptidão.

Foi determinada pelo Conselho Nacional de Política Energética (CNPE) a obrigatoriedade de compra, por meio de leilões, de biodiesel com o Selo Combustível Social pelos produtores e importadores de óleo diesel mineral para cumprir exigência da mistura de biodiesel no volume do diesel, conforme Resolução $n \stackrel{0}{0}$ 3, de 23 de setembro de 2005 (Diário Oficial da União, 2005). Os compradores do biodiesel nos leilões são os produtores e importadores de óleo diesel, estas podem adquirir um volume de biodiesel proporcional a sua participação no mercado nacional de óleo diesel, sendo que a Petrobras representa 93,3\% e a REFAP $6,7 \%$. Já os fornecedores de biodiesel podem ofertar nos leilões um volume limitado à sua capacidade anual de produção certificada pela ANP. O quadro regulatório definido pelo governo direciona a produção e consumo de biodiesel no cumprimento dos objetivos e metas propostos pelo PNPB, por meio da regulamentação do mercado, dos incentivos fornecidos pela aquisição do selo e das leis, normas e decretos que regulam setor de biodiesel.

O Selo Combustível Social é uma ação política que exerceu grande influência na produção do biodiesel. Uma vez que incentiva de forma contundente a participação da agricultura familiar na cadeia de suprimento, por meio de incentivos fiscais, reduções de alíquotas tributárias e como condição básica para que os produtores de biodiesel possam participar dos leilões dentro da cota reservada para lances de produtores com o Selo.

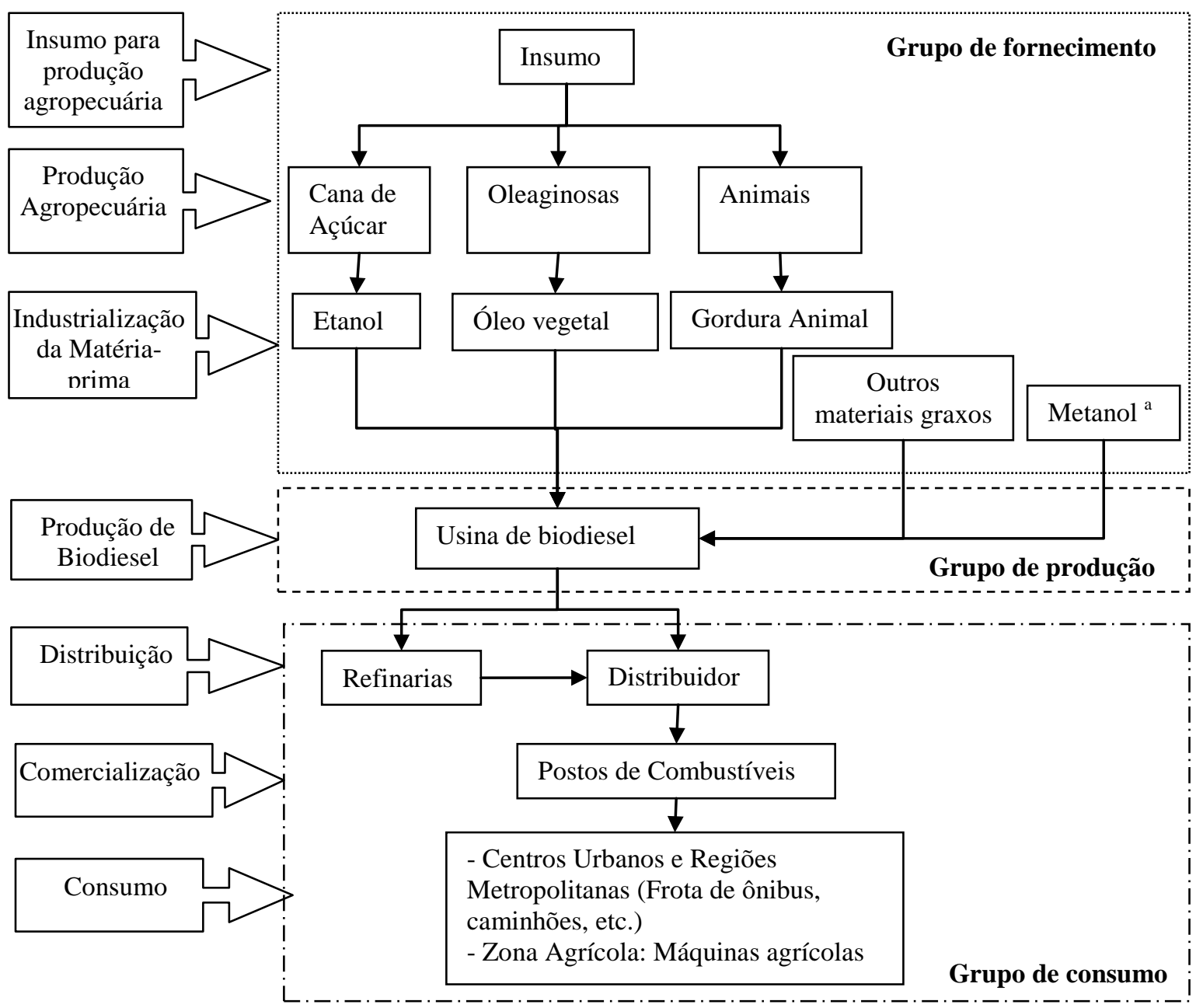

Figura 2: Desenho simplificado da cadeia de suprimento do biodiesel

Nota. Fonte: Adaptado de Santos, M. S. (2009). O Quadro Institucional do Biodiesel e suas Implicações nas Cadeias de Suprimento: Um Estudo de Casos Múltiplos no Estado do Rio Grande Do Sul. Dissertação de Mestrado, Universidade Federal do Rio Grande do Sul, Porto Alegre, RS, Brasil.

a Tem origem na indústria petroquímica. 
O biodiesel pode ser obtido por diferentes processos, tais como, craqueamento, esterificação ou transesterificação. O processo tecnológico mais utilizado para a produção de biodiesel no Brasil é a transesterificação, na qual a molécula de glicerina presente na molécula de óleo é removida, sendo substituída pelo álcool, mantendo os ésteres da mesma. A Figura 2 traz o desenho da cadeia de suprimento do biodiesel, organizada em três grupos: o de fornecimento, o de produção e o de consumo.

No Estado do Rio Grande do Sul, em 2011 existiam sete usinas de biodiesel autorizadas e em operação, sediadas nos seguintes municípios: Veranópolis, Rosário do Sul, Passo Fundo, Cachoeira do Sul, ljuí, Erechim e Canoas. As capacidades produtivas das usinas são, respectivamente, de $378.000 \mathrm{~m}_{3} / a n o$, $129.600 \mathrm{~m}^{3} /$ ano, $159.840 \mathrm{~m}^{3} / \mathrm{ano}, 335.998,8 \mathrm{~m}^{3} / \mathrm{ano}, 234.000 \mathrm{~m}^{3} / \mathrm{ano}, 216.000 \mathrm{~m}^{3} /$ ano e $324.000 \mathrm{~m}^{3} / \mathrm{ano}$ (ANP, 2011).

A matéria-prima mais utilizada para a fabricação do biodiesel no estado, seguindo a tendência nacional, é o óleo de soja. A disseminação do uso do óleo de soja pelas usinas produtoras de biodiesel do Rio Grande do Sul teve como estímulo a existência de um sistema de produção, comercialização e suprimento da soja e do óleo de soja já consolidado no estado. Dessa forma, o biodiesel se firma como mais uma alternativa de mercado aos produtores de soja e esmagadoras, passando a integrar esse sistema agroindustrial.

As usinas de biodiesel, apesar de utilizarem o óleo vegetal como matéria-prima também compram grão para cumprir as regras do Selo Combustível Social ou para esmagá-la a façon, quando o custo pela aquisição do óleo for maior do que a compra do grão e seu esmagamento. Comumente, a compra referente à soja advinda da Agricultura Familiar feita pelos produtores de biodiesel ocorre por intermédio da cooperativa devido ao volume disponível para a comercialização.

\section{Procedimentos Metodológicos}

Para entender a forma como as transações entre os agentes influenciam a cadeia de suprimento do biodiesel no Rio Grande do Sul foram contemplados não só os membros primários, mas também os membros de suporte, sem restrição à dimensão que estes ocupam na estrutura da cadeia de suprimento do biodiesel no Rio Grande do Sul. As variáveis analisadas foram selecionadas a partir dos processos e componentes da cadeia de suprimento, optou-se por com: (i)processo de gestão do relacionamento com o consumidor; (ii) processo de gestão do serviço ao consumidor; (iii) processo gestão do relacionamento com o fornecedor; (iv) processo de desenvolvimento e comercialização, (v) estrutura do fluxo de produto; estrutura do fluxo de informação; e contratos. Já as categorias analíticas utilizadas na pesquisa basearamse nos elementos da transação, sendo: (i) a racionalidade limitada, (ii) o oportunismo, (iii) os ativos específicos, (iv) a incerteza e (v) a frequência da transação.

A partir das definições das variáveis e das categorias de análise foi realizado um estudo de casos múltiplos realizado em duas das seis cadeias de suprimento de biodiesel. De acordo com Yin (2005), este tipo de estudo de caso é caracterizado pela aplicação do esquema de análise em mais de um caso, por ser mais adequado para responder a questão de pesquisa.

O estudo de caso tem como foco não a forma de pesquisa em si, mesmo considerando a sua importância, mas sim o tipo de questão que pretende responder. O interesse está centrado no específico, em um conjunto de relações ou em um fenômeno individual, organizacional, social ou político (Godoy, 2006). Neste trabalho, optou-se por utilizar a cadeia de suprimento do biodiesel como objeto de estudo, uma vez que esta pode ser vista como conjunto de relações. Segundo Yin (2005), o estudo de caso contribui, em especial, para a compreensão dos fenômenos sociais, políticos, organizacionais e individuais complexos, e este método de pesquisa conserva, durante a análise, as características holísticas e significativas dos eventos da vida real.

A seleção dos casos tomou como base as usinas produtoras de biodiesel e levou em conta: (i) os maiores volumes vendidos nos leilões, (ii) as maiores capacidades de produção autorizadas pela ANP, (iii) a proximidade das plantas de produção em relação ao município de Porto Alegre, (iv) a acessibilidade direta e indireta às informações e ( $v$ ) a diversidade da estrutura da cadeia (presença ou não do presença do processo de esmagamento do grão na estrutura da empresa). Com base nesses critérios forem escolhidas as usinas localizadas em Veranópolis/RS e Passo Fundo/RS, denominadas respectivamente como US1 e US2, sendo que as cadeias de suprimento analisadas correspondem às cadeias dessas usinas, sendo referidas neste artigo como SC1 e SC2. 
A usina US1 iniciou sua atividade como produtora de óleo vegetal em 1980, em 2002 com a possibilidade de atuar no mercado de biodiesel optou por investir no setor e teve sua primeira planta inaugurada em 2007. Atualmente tem uma capacidade instalada de $378.000 \mathrm{~m}_{3} / \mathrm{ano}$ e participa ativamente dos leilões realizados pela ANP. A usina US2 US2 foi criada com o intuito de aproveitar a oportunidade de um novo negócio que surgia com a criação do PNPB pelo governo federal e dos incentivos contínuos para consolidar o biodiesel como uma fonte de energia renovável na matriz energética brasileira, iniciando sua operação em meados de 2006. Atualmente a empresa investe na sua planta esmagadora de grãos e conta com uma capacidade autorizada de $159.840 \mathrm{~m}^{3} /$ ano.

A pesquisa de campo utilizou várias técnicas e fontes de evidência para a coleta de dados, tais como: revisão bibliográfica, conversas informais com os atores pertencentes às cadeias de suprimento do biodiesel, participação em reuniões com alguns representantes dos elos das cadeias, reportagens de jornais, participação em eventos da área; relatórios do governo; entrevistas não-estruturadas e entrevistas semi-estruturadas. A utilização de diferentes fontes de evidência fornece maior suporte à confiabilidade do estudo de caso, em especial nos casos em que não é possível coletar todas as impressões e informações acerca do objeto em estudo por meio de apenas uma fonte.

As informações para esta pesquisa foram coletadas junto aos membros primários e de suporte da cadeia produtiva do biodiesel, ao longo de 2009. As entrevistas semi-estruturadas foram realizadas com os produtores de biodiesel de cada um dos casos, forma entrevistados o diretor de operações na US1 e o presidente do conselho da US2.

As entrevistas não estruturadas forma realizadas junto a dois representantes da Cooperativa C1, sendo o encarregado pelo departamento técnico, e o encarregado pelo departamento comercial, e com o encarregado pelo departamento comercial da Cooperativa C2, ambas mantêm relações comerciais com as usinas US1 e US2. Foram entrevistados, também, o coordenador da área de fomento e o coordenador administrativo da US2 e o gerente de gás e desenvolvimento automotivo da Distribuidora D1. Além dos membros primários da cadeia, foram entrevistados alguns membros de suporte, são eles: o técnico responsável pela divisão de biodiesel da FETAG, dois pesquisadores da EMBRAPA/ Clima Temperado Empresa Brasileira de Pesquisa Agropecuária -, o assistente técnico estadual da EMATER-RS - Empresa de Assistência Técnica e Extensão Rural do Estado do Rio Grande do Sul -, e o responsável pela divisão de biodiesel da FETAG-RS - Federação dos Trabalhadores na Agricultura do Estado do Rio Grande do Sul Agrícolas. Os nomes foram preservados a pedido dos entrevistados

Para a apreciação dos dados levantados foi realizada uma análise cruzada dos casos, por existir elos comuns nas duas cadeias de suprimento estudadas, tornando a análise mais dinâmica. O exame dos casos foi realizado em conjunto e simultaneamente para que se pudesse compreender melhor a relação entre as categorias analíticas referente às transações que ocorrem entre os membros da cadeia e as variáveis que compõe a estrutura da cadeia. A análise foi realizada logo depois da finalização da coleta de dados ainda durante o ano de 2009.

\section{Apresentação e Análise dos Dados}

\subsection{Processos e Elementos das Cadeias de Suprimento}

A análise dos processos e elementos das cadeias SC1 e SC2 foi baseada em três pontos que consideram as relações e transações existentes ao longo da cadeia e que contemplam mais de um membro da mesma: (i) a compra de matéria-prima para a produção do biodiesel, (ii) a comercialização e (iii) a distribuição deste biocombustível.

O grupo de fornecimento da cadeia SC1 localizado a montante da usina de biodiesel US1 é composto, basicamente, por cinco membros: (i) cooperativas, (ii) produtores familiares de grãos, (iii) produtores patronais de grãos, (iv) cerealista, (v) distribuidores de produtos químicos e (vi) distribuidores de metanol. Todos estes membros estão distribuídos no primeiro nível do grupo de fornecimento, por manterem relação direta com a usina. No entanto, os produtores de grãos (familiares e patronais), podem também ser localizados no segundo nível quando transacionam com as cooperativas ou cerealistas localizados no primeiro nível de fornecimento. Este grupo não é rígido, por existir mudança frequente, especialmente nos fornecedores do grão de soja.

Um dos motivos para essa troca de fornecedores de grãos é a falta de fidelidade entre produtores/cooperativas, produtores/usinas e cooperativas/usinas. Pois, as transações entre esses 
membros seguem uma lógica econômica, na qual os agentes que detêm a soja optam por vender a quem Ihes oferecer um preço mais atrativo. No entanto observou-se a existência de transações frequentes entre a usina US1 junto a algumas cooperativas e produtores, possibilitando a construção de relacionamentos mais próximos e fortes devido à confiança no cumprimento dos contratos firmados. Isto confirma os fundamentos que a ECT traz no que se refere à frequência da transação, onde, a reputação dos agentes é construída a partir do número de transações que corre e da forma como eles agiram durante as mesmas. A fidelidade dos agentes localizados no elo agrícola da cadeia é importante num ambiente no qual as quebras de contrato são comuns, mesmo quando estes são formais.

Na cadeia de suprimento SC2, o grupo de fornecimento tem uma formação similar, com a inclusão de mais dois membro, os esmagadores de grãos e os produtores de óleo. A compra de grãos pela usina US2 envolve diferentes membros da cadeia SC2. O grupo de fornecimento não apresenta uma estrutura fixa, uma vez que a usina US2 mantém relação e transaciona com diferentes atores, buscando sempre a melhor oportunidade de negócio para o momento. A compra de grãos pela usina US2 junto aos produtores, aos cerealistas, às cooperativas ou via corretora é feita em uma mesa de negociação sem estar restrita ao tipo de relacionamento existente entre fornecedor e usina e a localização do grão. O negócio é feito com o fornecedor que aceitar o preço proposto pela usina. Assim, as relações comerciais da usina são pautadas nos ganhos de cada um dos agentes, caracterizando a predominância do oportunismo nessas relações.

Aliado ao fato de as transações da usina US2 se basearem no ganho está o próprio oportunismo dos produtores rurais que optam por vender o grão aos agentes que lhe oferecerem a melhor condição de preço. Essas duas questões determinam os fornecedores e o tipo de relacionamento existente entre eles e a usina. Tanto a usina US1 como a usina US2 mantêm relações estritamente comerciais com os demais fornecedores, que não a agricultura familiar, sendo estas regidas pela lógica do mercado. Percebe-se que as características dos elementos e dos processos de negócio que envolve a aquisição de grão são parecidas na cadeia SC2 e SC1, pois a estrutura de compra de grãos pelas usinas e o tipo de relacionamento existente entre elas e seus fornecedores, são similares.

As cooperativas, apesar de não receberem destaque nas ações do governo federal direcionadas a cadeia do biodiesel, são importantes para os agricultores familiares. Elas fornecem a estes produtores a oportunidade de transacionar o seu grão no mercado a um melhor preço, pois o volume de grãos recebidos pela cooperativa assegura uma faixa de negociação para a sua venda. No entanto, esta proficuidade não garante a fidelidade dos agricultores, observa-se que o comprometimento destes com a cooperativa é inversamente proporcional ao volume de grãos produzido, quanto maior é o volume menor é a fidelidade. Além disso, não existe contrato entre produtores e cooperativa que garanta a entrega dos grãos, da mesma forma que ocorre nas relações de venda do grão para a usina, o produtor entrega na cooperativa apenas se esta tiver um preço satisfatório.

Apesar da similitude entre a estrutura de compra de grãos da SC1 e SC2, a presença das esmagadoras de óleo e dos produtores de óleo no grupo de fornecimento da SC2 diferencia a estrutura das duas cadeias. Por não produzir o óleo vegetal a US2 precisa adquirir este produto no mercado, ou então, comprar o grão e utilizar o esmagamento a façon. Esta estrutura de fornecimento do óleo vegetal faz com que a cadeia SC2 seja menos verticalizada do que a SC1 e com que o fluxo dos grãos seja configurado em rotas diferentes da SC1. A opção de comprar o grão ou o óleo leva em conta os preços de mercado do momento da negociação e a usina opta por adquirir o produto que Ihe for mais vantajoso.

Os contratos entre as usinas US1 e US2 com os fornecedores fora do que é regulado pelo Selo Combustível Social são firmados livremente, sem interferência do governo federal. Existe a predominância da dinâmica de mercado nessas transações, ou seja, independente do fornecedor, será a oferta do melhor preço que determinará a venda e em alguns casos a frequência das transações.

No que tange a comercialização do biodiesel, observou-se que é bastante controlada, o governo tem influência na forma como os membros envolvidos nesse processo se relacionam. A intervenção do governo federal existe para que haja garantia de qualidade e oferta de biodiesel, isso resulta numa formalização dos relacionamentos entre a usina e os membros localizados no primeiro e segundo nível do grupo de fornecimento.

A transação passa a ter pouca influência neste contexto, ao passo que as pressões institucionais estruturam e definem os relacionamentos entre os membros. A determinação da compra via leilões, promovidos pela ANP, faz com que as transações entre a US1 e US2 e as refinarias não tenham frequência determinada já que dependem dos resultados dos leilões e não da intenção de compra e venda entre os 
membros. As relações assumem um caráter formal, com contratos claros e bem definidos, parametrizadas por mecanismos legais.

Toda a transação entre as usinas e as refinarias é acompanhada pela ANP, que, além de regular o setor, também é responsável por divulgar e convocar os leilões e por gerenciar as informações sobre o mercado de biodiesel, os volumes produzidos e comercializados, a qualidade do biodiesel e as matériasprimas utilizadas na produção. Todo o processo que envolve o leilão e as entregas do biodiesel é monitorado pela ANP, que recebe as informações tanto da Petrobras como das usinas e distribuidoras de combustíveis.

\subsection{Os Componentes da Transação e os Componentes e Processos da Cadeia de Suprimento}

O comportamento das organizações é resultado não só das pressões institucionais do ambiente no qual estão inseridas, mas também das suas transações. Sendo assim, as cadeias de suprimentos são influenciadas pelas transações que ocorrem entre seus membros e pelo ambiente institucional no qual se insere. Para a ECT, as transações dependem de dois fatores (os pressupostos comportamentais e os atributos da transação) que em conjunto determinam a maneira como os membros das cadeias se relacionam e se organizam. Para identificar a forma como os fatores da transação estão presentes na cadeia de suprimento do biodiesel, foram analisados alguns processos de negócio e os componentes da cadeia de suprimento.

Os atributos explicam o porquê de uma transação ocorrer de certa maneira e os elementos que compõem esta categoria analítica são a incerteza, a frequência e a especificidade do ativo. Os fatos que evidenciam essas categorias podem ser descritos pelas incertezas quanto às ações do governo e entregas no volume contratado de grãos pela agricultura familiar, conflitos de interesse entre os membros da cadeia, fidelização entre os membros da cadeia, confiança nas relações e criação de projetos juntamente a agricultura familiar, buscando fomentar outras oleaginosas.

A partir dos pressupostos comportamentais é possível compreender melhor a forma como os agentes econômicos se relacionam, determinando também a forma como a transação ocorre. A análise destes toma como base o oportunismo e a racionalidade limitada dos agentes da transação. As palavras-chaves para esta categoria são: oportunismo, racionalidade limitada, fidelidade, comprometimento, incerteza, contratos e salvaguardas.

\subsubsection{Processo de gestão do relacionamento com o consumidor e processo de gestão do serviço ao consumidor}

As transações entre agricultor familiar e as usinas US1 e US2 ou cooperativas, ocorrem de forma direta e com a presença da incerteza no cumprimento dos acordos por parte da agricultura familiar, decorrência da falta de fidelidade entre eles. O ganho econômico direciona as opções do produtor agrícola e, mesmo com contrato firmado junto a usinas e cooperativas, no ato da entrega pode ocorrer quebra de contrato, pelo agricultor vislumbrar maiores ganhos em outra transação. Percebe-se que as transações estão baseadas nas oportunidades dos agentes e não na sua frequência ou na fidelização.

O oportunismo ex-post é uma característica marcante dos produtores familiares, que optam por romper os contratos firmados com as usinas ou cooperativas para transacionar com outro agente que o ofereça um valor superior ao acordado, evidenciando a ausência de fidelidade dos produtores familiares para com os seus clientes. Esse comportamento resulta numa falta de confiança que se torna um problema para a cadeia, principalmente por se tratar de negociações com contratos simples e com poucas salvaguardas, onde a palavra muitas vezes tem maior validade do que um contrato formal.

Já a relação entre usinas e distribuidoras de combustíveis não se estabelece diretamente, pois, as refinarias fazem o intermédio entre esses atores, por meio dos leilões, dificultando a construção de relacionamentos baseados na confiança e na frequência das transações. No entanto, a qualidade e a pontualidade e entrega do produto possibilita a construção de um relacionamento de confiança entre esses agentes, direcionamento as opções de compra das distribuidoras a um mesmo fornecedor.

Nas transações de compra e venda de biodiesel, o oportunismo é atenuado pela alta regulação do mercado. O fato de a compra e a venda serem realizadas em leilões reduz a incerteza dos agentes quanto à transação, uma vez que toda a negociação é aberta e formalizada. Assim, independente dos agentes 
envolvidos, todos os contratos seguem o mesmo formato, com salvaguardas bem definidas e sanções claras e rígidas, buscando assegurar o cumprimento dos acordos.

\subsubsection{Processo de gestão do relacionamento com o fornecedor}

Do ponto de vista das usinas, as transações que ocorrem com a agricultura familiar são cercadas de incertezas que vão além das dúvidas relacionadas às questões climáticas e aos preços que afetam o mercado de grãos, a insegurança está no cumprimento dos contratos pela agricultura familiar. O mesmo ocorre com as negociações entre cooperativas e produtores familiares. O oportunismo existente nessas transações amplia as incertezas quanto à entrega do grão, tornando a racionalidade limitada da usina mais evidente.

Dois pontos que reduzem a incerteza puderam ser identificados: a frequência da transação e o Selo Combustível Social. A frequência com que ocorrem as trocas faz com que o oportunismo seja reduzido, aumentando a confiança entre os agentes e a fidelidade entre as partes. Já os contratos firmados pelo Selo Combustível Social reduzem a incerteza quanto à entrega, graças à existência de um bônus sobre o preço de mercado pago pelo grão, traduzido em ganho econômico para agricultor familiar. Assim, as usinas procuram negociar com aqueles fornecedores que já mantêm relação, por conhecer sua reputação.

No caso da oleaginosa negociada ser a soja, o oportunismo dos agentes é reforçado pela baixa especificidade do ativo, que, por ser uma commodity, pode ser facilmente comercializada no mercado, não havendo a necessidade de os fornecedores serem fiéis aos seus clientes, e vice-versa, buscando assim a transacionar com quem melhor paga. Essa lógica impera em quase todas as relações entre as usinas e as cooperativas com os produtores familiares, percebe-se que em alguns casos as usinas conseguem manter uma relação baseada na confiança e na frequência da transação, reduzindo a incerteza da entrega e da qualidade do produto adquirido. Quanto às relações entre a Petrobras e as usinas e entre as distribuidoras de combustíveis e seus fornecedores observa-se que o oportunismo é reduzido pela estrutura legal que abrange toda a comercialização do biodiesel, garantindo o cumprimento dos contratos. Isso reduz as incertezas quanto à entrega do biodiesel pelas usinas, uma vez que existem sanções bem claras e definidas para aqueles que não cumprirem com seus acordos.

\subsubsection{Processo de desenvolvimento e comercialização}

A partir da dificuldade das usinas em substituir a soja como principal matéria-prima e dos incentivos do governo a inclusão da agricultura familiar, as usinas US1 e US2 se uniram a alguns produtores familiares com o intuito de fomentar oleaginosas alternativas à soja. A US2 tem trabalhado com o plantio da canola nas propriedades familiares e iniciará o mesmo projeto com o girassol. Já a US1 trabalha com a mamona. Nos dois casos houve uma aproximação entre as usinas e os produtores, modificando a estrutura de relacionamento entre eles a partir da confiança. Esses projetos reduzem o oportunismo que paira sobre as transações entre as usinas e os produtores familiares, uma vez que, com a proximidade e interesses comuns entre eles contribuem para a construção de uma relação de fidelidade.

\subsubsection{Estrutura do fluxo de produto}

A frequência das interações entre as usinas e distribuidoras de combustíveis e o histórico da qualidade e das entregas do produto reduz as incertezas quanto ao recebimento do produto e traz confiança ao relacionamento, influenciando nas decisões de compra da distribuidora de combustíveis. O fluxo de produto está ligado às vendas de biodiesel nos leilões; no entanto, é influenciado indiretamente pelas opções de compra das distribuidoras de combustíveis nos releilões, atuando também sobre o direcionamento do produto. A distribuição do biodiesel é formalmente dirigida e controlada pelos mecanismos legais definidos pelo governo, fazendo com que o oportunismo e a racionalidade limitada tenham pouca influência sobre este processo.

\subsubsection{Estrutura do fluxo de informação}

O governo federal, além de atuar ativamente sobre o mercado do biodiesel, também concentra as informações sobre as atividades e desempenho do setor. No contexto em que ocorrem as transações, as 
incertezas quanto às ações do governo são oriundas da centralização das informações do setor pelo governo e da falta de um canal de comunicação mais aberto e direto entre os membros da cadeia. A informação a respeito dos leilões de venda é formalizada e todas as usinas têm acesso ao mesmo nível de informação, não sendo observada uma influência relevante do oportunismo ou da racionalidade limitada nesta etapa da comercialização do biodiesel.

\subsubsection{Contratos}

Mesmo com a incerteza e o oportunismo nas transações entre agricultores familiares e usinas, os contratos de compra e venda de grãos são simples e com poucas salvaguardas. Neste mercado, a "palavra" tem mais força e legitimidade que o contrato formal entre os agentes. Os contratos formais firmados dentro do contexto do Selo Combustível Social têm maior peso legal, as usinas reconhecem essa força pela existência das punições e sanções decorrentes do seu descumprimento, minimizando atuação de maneira oportunista dos membros.

\section{Conclusões e Recomendações}

A pesquisa buscou analisar a forma como as transações que ocorrem entre os diversos elos da cadeia de suprimento de biodiesel no Rio Grande do Sul influenciaram sua a estrutura. A partir do levantamento realizado nas duas cadeias de suprimento, SC1 e SC2 percebeu-se uma estruturação similar, a partir dos incentivos e programas do governo federal. A maneira como o grupo de consumo se organizou nas duas cadeias segue as determinações do quadro regulatório que normatiza e controla a comercialização e distribuição do biodiesel. Já no grupo de fornecimento algumas das transações operam sob a lógica do mercado e outras ocorrem sobre o abrigo do PNPB ou do Selo Combustível Social. Observase a existência de transações tangenciadas por características institucionais da cadeia.

No grupo de fornecimento as transações mais pautadas pelas pressões institucionais advindas do quadro regulatório ocorrem entre as usinas e os produtores familiares. Pois, estando dentro da abrangência do Selo Combustível Social as transações são guiadas por diretrizes e normas definidas pelo programa. As relações entre os demais membros do grupo de fornecimento (produtores patronais de grãos, cerealista, distribuidores de produtos químicos, distribuidores de metanol, os esmagadores de grãos e os produtores de óleo) ocorrem de forma independente ao quadro institucional do biodiesel. Isso pode ser explicado pela não existência de programas específicos ou leis direcionadas para as transações que ocorrem entre os estes. Assim, a configuração dessas interações segue a lógica do mercado, que preza pela busca do ganho máximo sem interferência das pressões institucionais do quadro criado pelo governo federal.

A existência marcante do oportunismo nas relações em que a agricultura familiar participa faz com que os produtores familiares, algumas vezes, descumpriam os contratos com as usinas ou com as cooperativas, para transacionar o grão com outro agente que ofereça um preço maior no produto. Isso faz com que as transações que ocorrem junto a este membro seja envolta de incertezas, em especial no que se refere a entrega dos produtos. A baixa frequência das transações também contribui para o aumento das incertezas, dificultando o relacionamento entre esses atores, fato observado nas mudanças frequente de fornecedores de matéria-prima, influenciando, assim, a estruturação da cadeia

O Selo Combustível Social contribuiu para estreitar a relação entre os agentes, reduzindo as incertezas e o oportunismo ex-post, por parte da agricultura familiar, presentes nas transações. Com a aquisição do Selo Combustível Social as usinas passam a ter que firmar contratos com salvaguardas mais bem definidas, assegurando o valor do grão a ser pago e a prestação de assistência técnica, por exemplo. Aliado a isso, o bônus dado sobre o valor do grão pago ao produtor contribuiu para que as transações junto às usinas se tornassem mais atrativas aos olhos dos produtores familiares, minimizando a intenção deste em agir de forma oportunita. Com isso a variação de fornecedores tende a diminuir e quanto maior a confiança nas relações de troca com os agricultores familiares, maior é a frequência das transações, tornando a estrutura da cadeia menos variável.

As intervenções do governo federal na cadeia, por meio das regulamentações e programas, limitam a dinâmica do mercado e de certa forma a própria competitividade das usinas. A definição do formato de comercialização do biodiesel e a limitação da compra a leilões com volumes limitados e preços máximos restringem as estratégias das empresas e as suas possibilidades ganho. Isso faz com que as influências das transações sejam observadas em menor grau no grupo de consumo, do que no grupo de fornecimento. 
Pois, no grupo de consumo, por receber grande influência institucional, os atributos da transação e os pressupostos comportamentais exercem pouca influencia sobre a estrutura deste grupo

Ressalta-se a importância que o oportunismo e as incertezas tiveram na organização do grupo de fornecimento e a marcante presença de um quadro institucional regulatório no grupo de consumo. Observou-se que a presença do quadro regulatório resulta numa redução do oportunismo e das incertezas nas transações, portanto, a estrutura das cadeias é moldada não só pelos atributos da transação e os pressupostos comportamentais, mas também pelas pressões institucionais que atuam sobre ela. Não faz parte do escopo deste trabalho analisar se é a transação ou as pressões institucionais que exerce maior influencia sobre estrutura, mas é possível dizer que na cadeia do biodiesel no Rio Grande do Sul, as transações sofrem pressões institucionais.

\section{Referências}

ANP (2011). Capacidade autorizada-biodiesel. Disponível em:

http://www.anp.gov.br/?pg =29048\&m=\&t1 =\&t2=\&t3=\&t4=\&ar=\&ps=\&cachebust=1345162687446.

Brasil, Lei 11.097, sancionada dia 13 de janeiro de 2005 (2009a). Dispõe sobre a introdução do biodiesel na matriz energética brasileira. Disponível em:

http://comunidades.mda.gov.br/portal/saf/programas/biodiesel/2290882

Brasil, Decreto Presidencial de 23 de dezembro de 2005 (2009b). Institui a omissão Executiva Interministerial encarregada da implantação das ações direcionadas à produção e ao uso de óleo vegetal biodiesel como fonte alternativa de energia. Disponível em:

http://www.planalto.gov.br/ccivil_03/dnn/2003/Dnn10093.htm.

Brasil, Instrução Normativa no 01, de 05 de julho de 2005 (2009c). Dispõe sobre os critérios e procedimentos relativos à concessão de uso do selo combustível social. Disponível em: http://comunidades.mda.gov.br/portal/saf/programas/biodiesel/2290882

Coase, R. H. The nature of the firm. Econômica, 4(16), 386-405. http://dx.doi.org/10.1111/j.14680335.1937.tb00002.x

Cooper, M. C. \& Ellram, L. M. Characteristics of Supply Chain Management and Implications for Purchasing and Logistics Strategy. The International journal of Logistics Management, 4(2), 13-24.

http://dx.doi.org/10.1108/09574099310804957

Cooper, M. C., Lambert, D. M. \& Pagh, J. D. (1997) Supply chain management: more than a new name for logistic. The International journal of Logistics Management, 8(1), 1-14. http://dx.doi.org/10.1108/09574099710805556

Croxton, K. L., García-Dastugue, S. J., Lambert, M. \& Rogers, D. S. (2001). The Supply Chain Management Process. The international Journal of Logistics Management, 12(2), 13-36.

http://dx.doi.org/10.1108/09574090110806271

D'Cruz, J. R \& Rugman, A M. (1997). Blending the Supply Chain into a Cohesive Business System. European Management Journal, 15(4), 25-28.

Diário Oficial da União (2005). Resolução n.3, de 23 de setembro. Edição nำ187.

Fredendall, L. D.\& Hill, E.(2001). Basis of Supply Chain Management. Boca Raton: St. Lucie Press.

Godoy, A. S. (2006) Estudo de caso qualitativo. In: GODOI, C. K.; MELLO, R.; SILVA, A. B. (Org.). Pesquisa Qualitativa em Estudos Organizacionais: Paradigmas, estratégias e métodos. São Paulo: Saraiva.

Hammer, M. \& Champy, J. (1994) Reengenharia revolucionando a empresa em função dos clientes, da concorrência e das grandes mudanças da gerência. Rio de Janeiro: Campus, 22.ed.

Harrington, J. H. (1993) Aperfeiçoando processos empresariais. São Paulo: Makron Books.

Knight, F. (1972). Risco, Incerteza e Lucro. Rio de Janeiro: Nacional.

Lambert, D. M. (2001). Supply Chain Management: What does it involve? Supply Chain \& Logistic Journal, 4(4). 
Lambert, D. M. \& Cooper, M. C. (2000). Issues in supply chain management. The International/ourna/ of Logistics Management, 29, 65-83..

PNPB. Programa Nacional de Produção e Uso de Biodiesel (2005). Disponível em: <http://www.biodiesel.gov.br>. Acesso em: 10 jun. 2009.

Saes, Maria. S. M. (2000) Organizações e Instituições. In Zylbersztajn, D. \& Neves, M. F. (Org.). Economia e Gestão dos Negócios Agroalimentares: indústrias de alimentos, indústrias de insumos, produção agropecuária e distribuição (cap. 8, 165-186). São Paulo: Pioneira.

SAF/MDA (2009). Programa Biodiesel. Disponível em http://comunidades.mda.gov.br/portal/saf/programas/biodiesel

Samaranayake, P. (2005). A conceptual framework for supply chain management: a structural integration. Supply Chain Management, 10 (1), 47-59. http://dx.doi.org/10.1108/13598540510578379

Santos, M. S. (2009). O Quadro Institucional do Biodiesel e suas Implicações nas Cadeias de Suprimento: Um Estudo de Casos Múltiplos no Estado do Rio Grande Do Sul. Dissertação de Mestrado, Universidade Federal do Rio Grande do Sul, Porto Alegre, RS, Brasil.

Simon, H. A. (1997). Administrative Behavior. Nova York: Free Press.

Sinchi-Levi, D., Kaminsky, P. \& Simchi-Levi, E. (2000). Designing and Managing the Supply Chain: concepts, strategies and case studies. Boston: Irwin MacGraw-Hill.

Williamson, O. E. (1981). The Economics of Organization: The Transaction Cost Approach. The American Journal of Sociology, 87 (3), Nov, 548-577. http://dx.doi.org/10.1086/227496

Williamson, O. E. (1985). The Economic Institutions of Capitalism: firms, markets, relational contracting. New York: The Free Press.

Williamson, O. E. (1996). The mechanisms of governance. New York: Oxford.

Williamson, O. E. (2000). The New Institutional Economics: Taking stock, looking ahead. Journal of Economic Literature, 38 (3), 595-613. http://dx.doi.org/10.1257/jel.38.3.595

Yin, R. (2005). Estudo de Caso: planejamento e métodos. Porto Alegre: Bookman.

Zylbersztajn, D. (2005). Papel dos contratos na coordenação agro-industrial: um olhar além dos mercados. $R E R, 3,385-420$.

Zylbersztajn, D. \& Farina, E. M. M. C. (1999). Strictly Coordinated Food - Systems: Exploring the limits of the Coasan Firm. International Food and Agrobusiness Management Review, 2 (2), 249-265.

http://dx.doi.org/10.1016/S1096-7508(00)00014-8 